Research Article

\title{
Achievement of Various Widebands: A Design of Wide-Slot Antennas Using Shape Blending
}

\author{
Aiting Wu $(\mathbb{D}$, Zhonghai Zhang, Boran Guan, and Liang Peng \\ College of Electronics and Information, Hangzhou Dianzi University, No. 1158 2nd Street, Xiasha District, Hangzhou 310018, China \\ Correspondence should be addressed to Aiting Wu; wuaiting@hdu.edu.cn
}

Received 3 January 2018; Revised 7 March 2018; Accepted 19 March 2018; Published 24 April 2018

Academic Editor: Jaume Anguera

Copyright (c) 2018 Aiting Wu et al. This is an open access article distributed under the Creative Commons Attribution License, which permits unrestricted use, distribution, and reproduction in any medium, provided the original work is properly cited.

\begin{abstract}
When designing printed wide-slot antennas, the shape or profile of the tuning stub is a key geometric structure that affects the impedance bandwidth of the antenna. This article introduces a new process for designing tuning stub shapes, which are the blended results of a diamond and a circle. By using different geometry shapes, the design could generate a series of bandwidths with a regular trend. Detailed investigations and analysis were conducted on some key geometry parameters to explore their impact on the impedance bandwidth of the antenna. To certify the new design method, several prototypes were simulated, developed, and measured. The experimental and simulated results showed good agreement with each other. The results indicate that by properly selecting various blended shapes, a BW range from 80.1 to $117.3 \%$ for a VSWR of less than 2 could be obtained, which provides a convenient model for a wideband antenna design.
\end{abstract}

\section{Introduction}

Printed slot antennas have gained popularity in a wide range of applications due to their simple structure and compactness. The antennas have an intrinsically narrow impedance bandwidth that hinders wide-bandwidth applications [1].

Several research efforts have made incremental improvements to mitigate this weakness. Among the various research investigations, widening the slot size was an efficient approach to increase the antenna bandwidth. The initial pioneering work focused on optimizing the geometry of the slot shape to improve the bandwidth [1]. Coplanar waveguide- (CPW-) fed slot antennas are another important kind of wideband antenna. Similarly, by appropriately designing the shape of the stub and slot, the antenna bandwidth could be considerably optimized. In [2], a slot antenna with a circular tuning stub and a circular slot has been investigated, which produces a bandwidth of $143.2 \%$. Later, similar attempts were conducted for wideband antennas [3-7].
Designing antennas to specifically obtain a preferred or required impedance bandwidth is typically not optimal because of its limited application; because any antenna design heavily relies on the experience of the designers, limited application antennas are not economical. Evolution algorithms were introduced next; they were used to ensure the design process is more automatic and intelligent [8-13]. Instead of the evolution algorithms, which require multiple iterations, another attempt is to build various bandwidths using a single-design process [14-16].

Based on our previous research work in $[17,18]$, a novel design method called the shape blending algorithm is proposed when optimizing the shape of the tuning stub. To build a rectangular slot antenna, a series of shape transformations using a shape blending process was used. The blending was made using a diamond and a circular shape; the tuning stub generated a continuous set of impedance bandwidths. The parametric analysis on the shape blending coefficient is performed to explore its impact on the antenna bandwidth. 


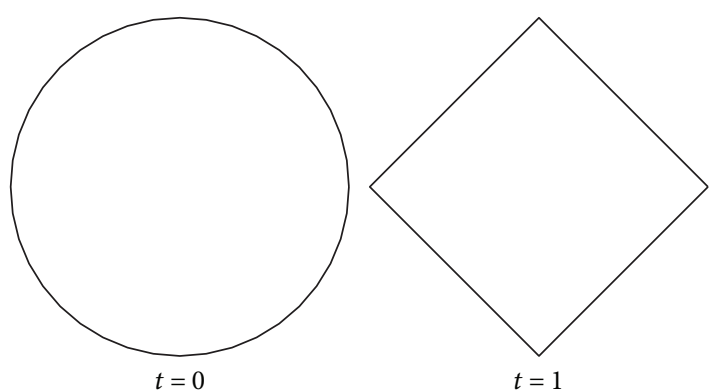

Figure 1: A circle and a diamond for the source and destination, respectively.

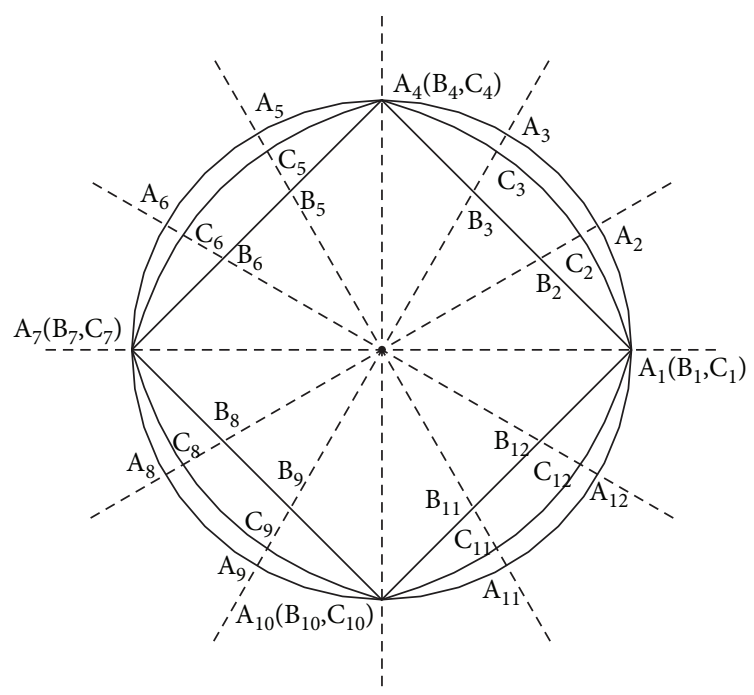

FIGURE 2: Illustration of the Ray firing algorithm.

\section{Shape Blending}

Shape blending is a transformation process that changes one shape into another via a series of intermediate steps [19], generally interchangeable with shape morphing and shape averaging. The process was originally developed by computer science researchers and engineers and has been playing an important role in the field of computer graphics and animation. Later, the technique soon spread to other domains [20, 21].

In this paper, shape blending is used to produce the antenna's geometric structures (e.g., tuning stub) that results in various impedance bandwidths. The first step is to determine the shape for the source and the destination, as shown in Figure 1. The source is a circle while the destination is a diamond.

Vertex correspondence and path interpolation are the two major obstacles to overcome in the next two steps. If both the source and the destination were polygons, with an equivalent number of vertices, the vertex correspondence process could be reduced to establish a corresponding relationship between the vertices. Generally, the vertices representing a shape are chosen to indicate its topological characteristics; therefore, many correspondence methods

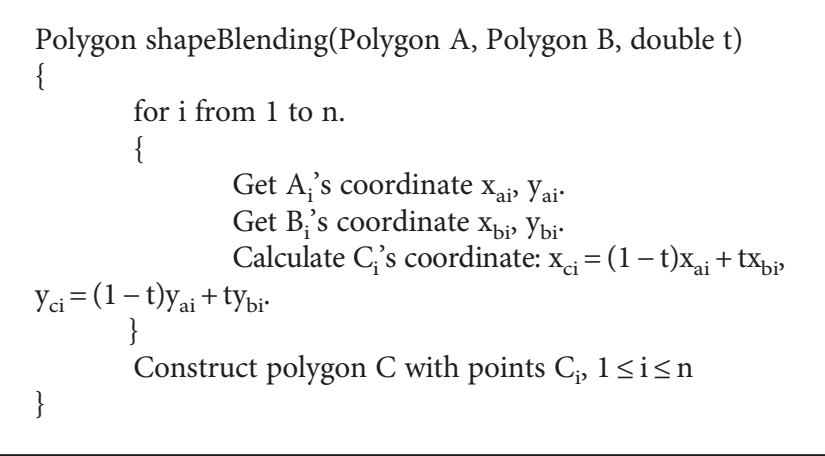

Algorithm 1: Polygon shapeBlending pseudocode.

have been developed and investigated. In this paper, the ray firing method is used for the vertex correspondence problem because of its simplicity and ability to process basic geometric shapes. As illustrated in Figure 2, the circle and the diamond are positioned so that their centers overlap with each other. Several rays originate from the center, and each ray intersects with the two shapes. The two intersected points on the same ray are paired. In this way, the vertices $A_{1}-A_{12}$ have correspondence with the vertices $B_{1}-B_{12}$, respectively.

Once the correspondence is established, the blended overlapping shapes can be measured using the corresponding vertices. The computation is done by either linear interpolation or some other tricky spline curve interpolation between each pair of corresponding vertices. Therefore, this process is called path-interpolation. From another perspective, the method determines how a vertex $A_{n}$ moves to the corresponding point $\mathrm{B}_{n}$. As shown in Figure 2, we adopt a basic linear interpolation. For example, the blended polygon $\mathrm{C}$ could be characterized by

$$
\begin{aligned}
\mathrm{C}(t) & =(1-t) \mathrm{A}+t \mathrm{~B}=\left[(1-t) \mathrm{A}_{1}+t \mathrm{~B}_{1}, \ldots,(1-t) \mathrm{A}_{n}+t \mathrm{~B}_{n}\right] \\
& =\left[\mathrm{C}_{1}(t), \ldots, \mathrm{C}_{n}(t)\right],
\end{aligned}
$$

where A and B are the source (the circle) and the destination (the diamond), respectively, and $n=12$. The parameter $t$ reflects the blending degree between the source and the destination, which is called the blending coefficient.

This process could be characterized by a function using the pseudocode recorded in Algorithm 1. The inputs of the function are two polygons, $\mathrm{A}$ and $\mathrm{B}$, which represent the source and the destination shape, respectively. The blending coefficient is $t$. Both $\mathrm{A}$ and $\mathrm{B}$ have $n$ vertices, $\mathrm{A}=\left[\mathrm{A}_{1}, \mathrm{~A}_{2}, \ldots, \mathrm{A}_{n}\right]$ and $\mathrm{B}=\left[\mathrm{B}_{1}, \mathrm{~B}_{2}, \ldots, \mathrm{B}_{n}\right]$. The return value of the function is a polygon $\mathrm{C}=\left[\mathrm{C}_{1}, \mathrm{C}_{2}, \ldots, \mathrm{C}_{n}\right]$ representing the resulting blended shape.

In the circle and diamond cases, we place both shapes in the same coordinate frame so their centers both lie at the origin point, as shown in Figure 3 . The radius of the circle is denoted as $r$. Since both the circle and the diamond are symmetric about the $x$-axis and $y$-axis, we only consider the first quadrant initially. A ray, $y=x \cos \alpha(0 \leq \alpha \leq \pi / 2)$, intersects with the circle and the diamond at $\mathrm{A}_{i}$ and $\mathrm{B}_{i}$, 


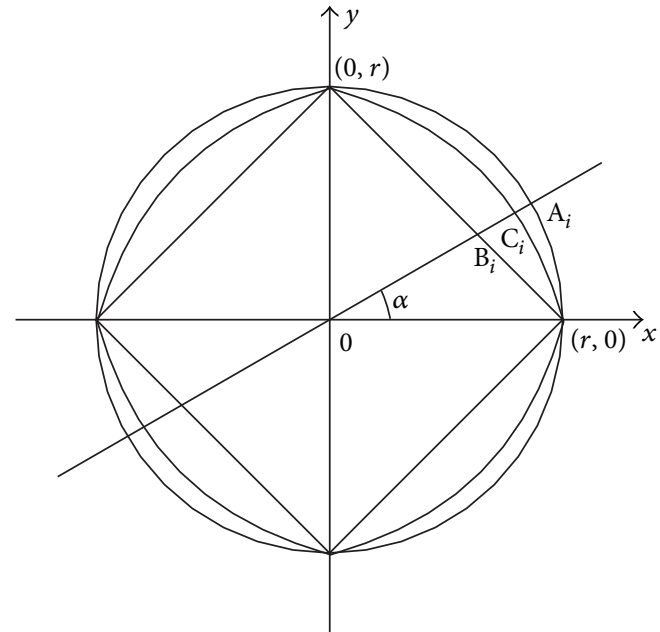

Figure 3: Shape blending calculation between a circle and a diamond.

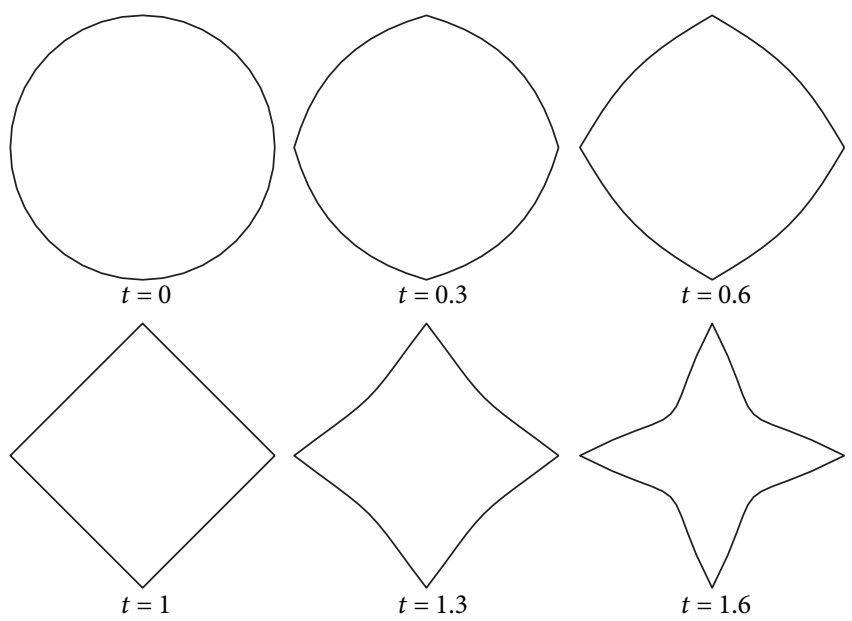

Figure 4: Blended results between a circle and a diamond with a variation of $t$ values.

respectively. It is straightforward to get the coordinates of the two corresponding vertices,

$$
\begin{aligned}
& A_{i}\left\{\begin{array}{l}
x_{a i}=r \cos \alpha, \\
y_{a i}=r \sin \alpha,
\end{array}\right. \\
& B_{i}\left\{\begin{array}{l}
x_{b i}=\frac{r \cos \alpha}{\cos \alpha+\sin \alpha}, \\
y_{b i}=\frac{r \sin \alpha}{\cos \alpha+\sin \alpha} .
\end{array}\right.
\end{aligned}
$$

Then a blended point $\mathrm{C}_{i}$ between $\mathrm{A}_{i}$ and $\mathrm{B}_{i}$ could be expressed as

$C_{i}\left\{\begin{array}{l}x_{c i}=(1-t) x_{a i}+t x_{b i}=(1-t) r \cos \alpha+t \frac{r \cos \alpha}{\cos \alpha+\sin \alpha}, \\ y_{c i}=(1-t) y_{a i}+t y_{b i}=(1-t) r \sin \alpha+t \frac{r \sin \alpha}{\cos \alpha+\sin \alpha}\end{array}\right.$

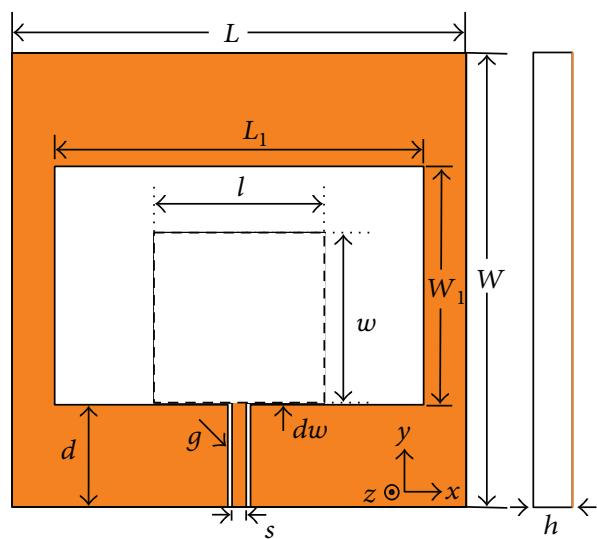

FIGURE 5: Antenna configuration.

The $\alpha$ value could be set to $i \pi / 2 m(0<i<m)$, which generates a set of points $C_{i}$. Likewise, we could get another three sets of points from the second, third, and fourth quadrants. All the points build the final blended polygon $\mathrm{C}$.

In this way, a series of blended results could be obtained, as shown in Figure 4. With different values of $t$, a series of blended results could be obtained, as shown in Figure 4 .

\section{Antenna Configuration}

Figure 5 displays the basic form of the proposed antenna and its geometry dimensions. The antenna is printed on a substrate with thickness $h=0.508 \mathrm{~mm}$, and the relative permittivity is $\varepsilon_{r}=3.66$ with a size of $L^{*} W$. The rectangular slot size is denoted as $L_{1}{ }^{*} W_{1}$. The width and the length of the feed line are $s$ and $d+d w$, respectively, which is connected to a tuning stub with an outline rectangle in $l^{*} w$, as shown in dashed lines in Figure 5. The feed line gap on the ground plane is $g$. The shape blending method, described in Section 2, is used to develop the geometry of the antenna tuning stub. The tuning stub has an offset above the bottom edge of the wide slot, which is denoted by $d w$.

To determine the layout parameters of the antenna, ANSYS HFSS software is used for the simulation and optimization. The final dimensions of the developed prototype are listed in Table 1.

\section{Parametric Study}

With the other geometry parameters fixed, the tuning stub shape is provided by the $t$ values, which primarily determines the antenna bandwidth. Therefore, various shapes could be constructed by varying the values of $t$ and finally lead to the achievement of various bandwidths. The simulations of the proposed antennas with different $t$ values are conducted, and the simulated return loss results are plotted in Figure 6. The bandwidth has a minimum when $t=0$ and a bandwidth of $4.28 \mathrm{GHz}$. The bandwidth increases gradually as $t$ changes from 0 to 1 . When $t=1.3$, the bandwidth reaches a maximum of $9.64 \mathrm{GHz}$, extending from $2.48 \mathrm{GHz}$ to $12.12 \mathrm{GHz}$. As the value of $t$ continues to increase, the bandwidth begins to decrease. 
TABLE 1: Antenna geometry parameters.

\begin{tabular}{lccccccccc}
\hline$L$ & $W$ & $L_{1}$ & $W_{1}$ & $d$ & $g$ & $s$ & $d w$ & $l$ & $w$ \\
\hline $32 \mathrm{~mm}$ & $32 \mathrm{~mm}$ & $26 \mathrm{~mm}$ & $16.8 \mathrm{~mm}$ & $7.2 \mathrm{~mm}$ & $0.2 \mathrm{~mm}$ & $1.0 \mathrm{~mm}$ & $0.13 \mathrm{~mm}$ & $12 \mathrm{~mm}$ & $12 \mathrm{~mm}$ \\
\hline
\end{tabular}

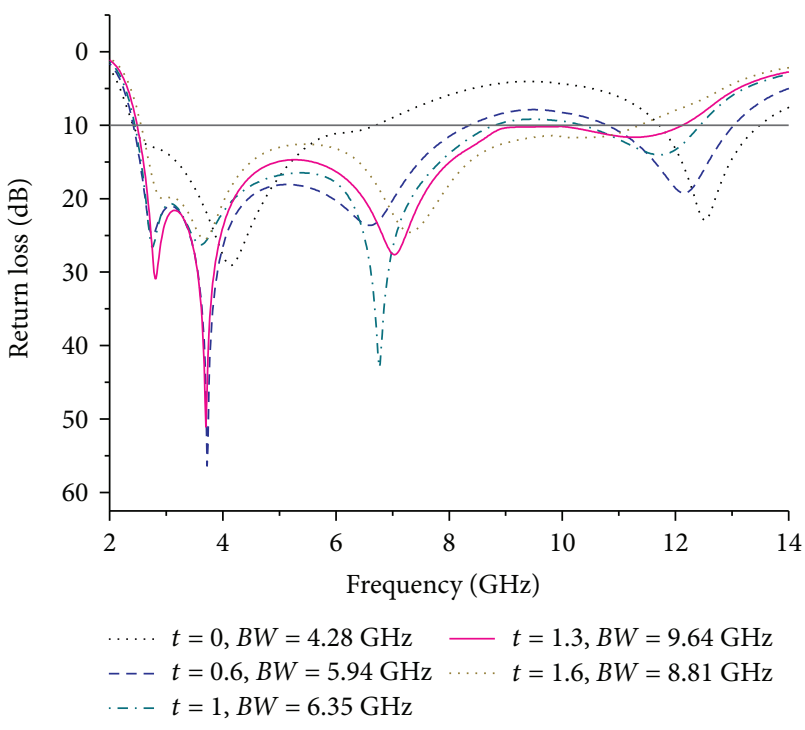

FIGURE 6: Simulated return loss results for different $t$ values.

Actually, the idea behind the scene is as follows: we first simulate the VSWR result of the circle (at $t=0)$ and the diamond (at $t=1.0$ ), whose bandwidths are $4.28 \mathrm{GHz}$ and $6.35 \mathrm{GHz}$, respectively. The characteristic of the shape blending algorithm is that the blended result will have the properties of both the source circle and the destination diamond. Therefore, the blending shape for $0<t<1$ will likely result in a bandwidth between $4.28 \mathrm{GHz}$ and $6.35 \mathrm{GHz}$. In other words, the bandwidth is expected to gradually broaden as $t$ changes from 0 to 1 . When $t>1$, there are two possibilities: (a) the bandwidth will start to decrease immediately or (b) the bandwidth will continue to increase before it decreases. The simulated results turn out to be case b. From another perspective, the wide slot contributes to the first and second resonances, whereas the blended stub generates the third one [22]. Therefore, we could see that the variation of $t$ has a very little impact on the positions of the first two resonances. The coupling occurs somewhere between the tuning stub and the ground plane. When $t$ changes from 0 to 1.3 , the impedance matching of the first two resonances increases, which leads to the gradual widening of the frequency bandwidth.

Table 2 compares the simulated bandwidths (VSWR $\leq 2$ ) of various $t$ values. To better illustrate the impact of parameter $t$ on the antenna bandwidth, the bandwidth results in Table 2 are plotted in Figure 7.

Figure 8 shows the surface current distribution of the proposed design when $t=1.3$ at $2.8,3.6$, and $7.1 \mathrm{GHz}$, which are the frequencies of the three resonances, respectively. From [23], the resonant modes of the antenna heavily rely on the geometry dimension of the tuning stub. Figure 8(a) shows the current distribution of a wire
TABLE 2: Antenna impedance bandwidths using $t=0,0.3,0.6,1,1.3$, 1.6 , and 1.9.

\begin{tabular}{lcccc}
\hline$t$ & $\begin{array}{c}\text { Frequency } \\
\text { value }\end{array}$ & $\begin{array}{c}\text { Absolute } \\
\text { range }(\mathrm{GHz})\end{array}$ & $\begin{array}{c}f_{\mathrm{c}} \\
\text { bandwidth }(\mathrm{GHz})\end{array}$ & $\begin{array}{c}\text { Fractional } \\
\text { bandwidth }\end{array}$ \\
\hline 0 & $2.42-6.70$ & 4.28 & 4.56 & $93.86 \%$ \\
0.3 & $2.37-7.79$ & 5.42 & 5.08 & $106.7 \%$ \\
0.6 & $2.42-8.36$ & 5.94 & 5.39 & $110.20 \%$ \\
1 & $2.45-8.80$ & 6.35 & 5.625 & $112.89 \%$ \\
1.3 & $2.48-12.12$ & 9.64 & 7.3 & $132.05 \%$ \\
1.6 & $2.56-11.37$ & 8.81 & 6.965 & $126.49 \%$ \\
1.9 & $2.57-10.62$ & 8.05 & 6.595 & $122.06 \%$ \\
\hline
\end{tabular}

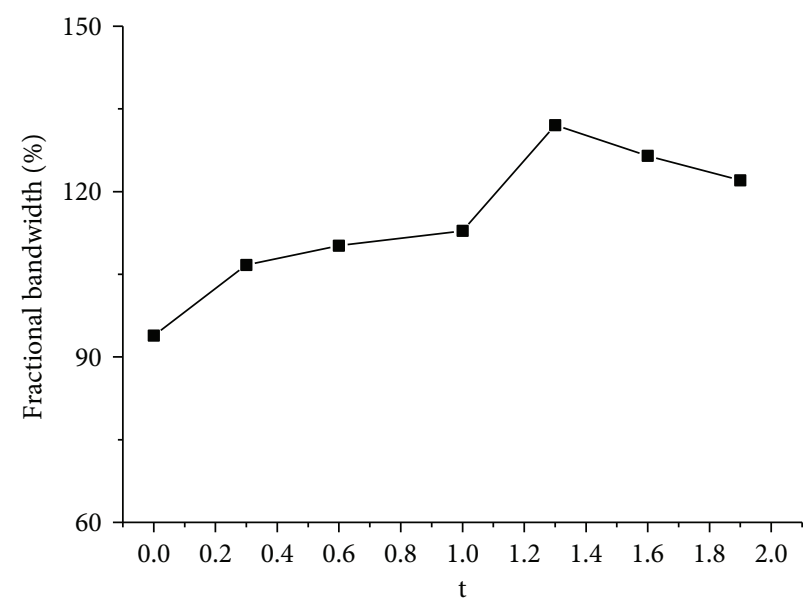

Figure 7: Antenna impedance bandwidths versus $t$ values.

monopole antenna with a quarter wavelength [24], and the antenna operates in fundamental mode at $2.8 \mathrm{GHz}$. The direction of the current is the same for both the ground plane and the stub, which means that a standing wave is formed in this case. At higher resonances (3.6 and $7.1 \mathrm{GHz}$ ), currents in the stub flow upward, while the currents in the ground plane flow in the opposite directions, as shown in Figures 8(b) and 8(c); this indicates that travelling waves dominate at these two resonances.

\section{Experiments}

To verify the analysis, several prototypes of the proposed antennas with a variety of tuning stubs $(t=0,0.3,0.6$, and 1.3) were developed. Figure 9 shows the fabricated prototypes. Table 3 lists both the simulated and the measured bandwidths of the prototypes.

Table 3 shows that the measured impedance bandwidths and the simulated ones approximately agree with each other. When $t$ changes from 0 to 1.3 , the measured absolute 


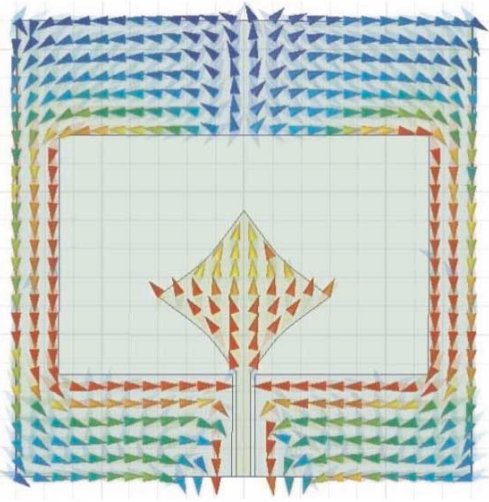

(a)

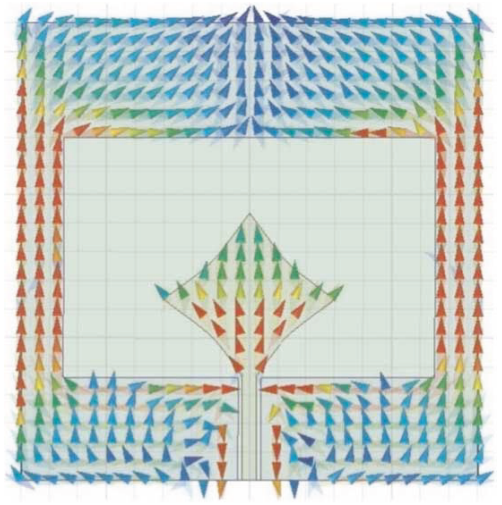

(b)

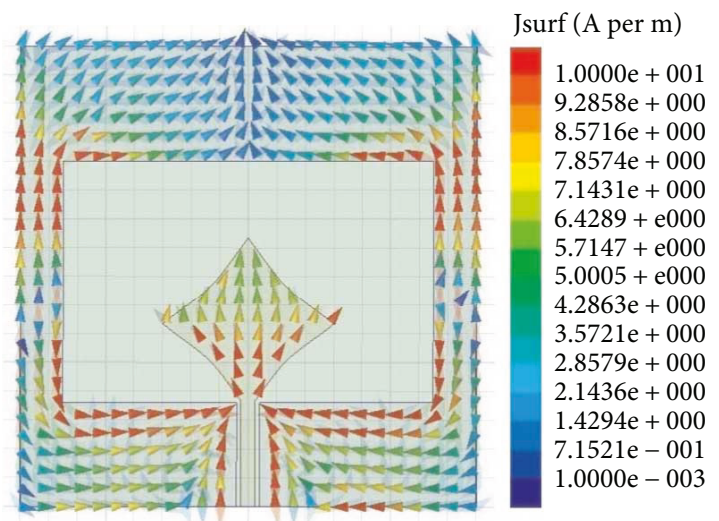

(c)

Figure 8: Simulated current distributions at (a) $2.8 \mathrm{GHz}$, (b) $3.6 \mathrm{GHz}$, and (c) $7.1 \mathrm{GHz}$.

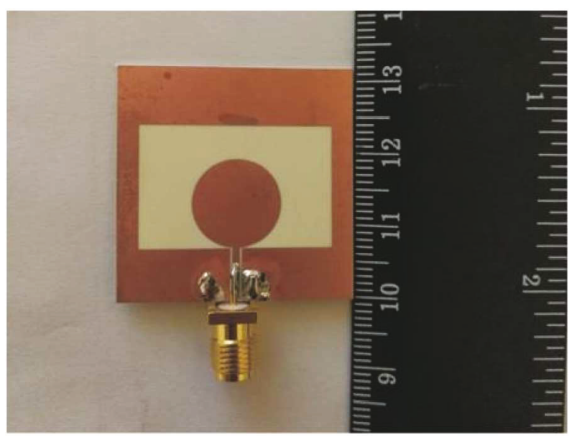

(a) Antenna 1

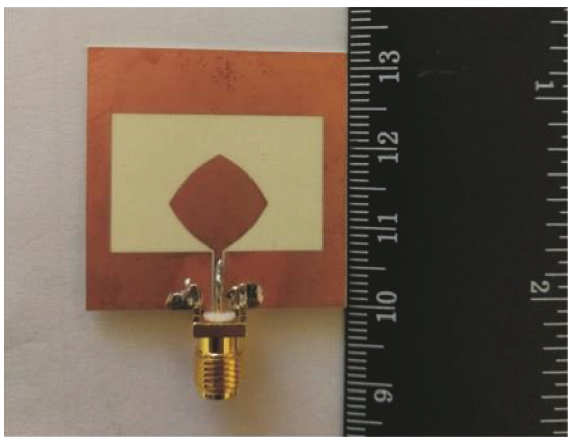

(c) Antenna 3

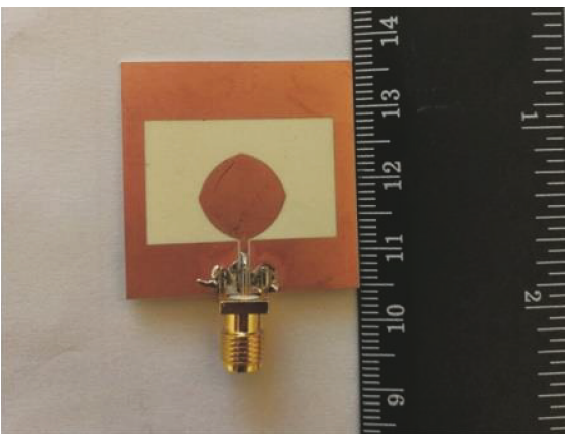

(b) Antenna 2

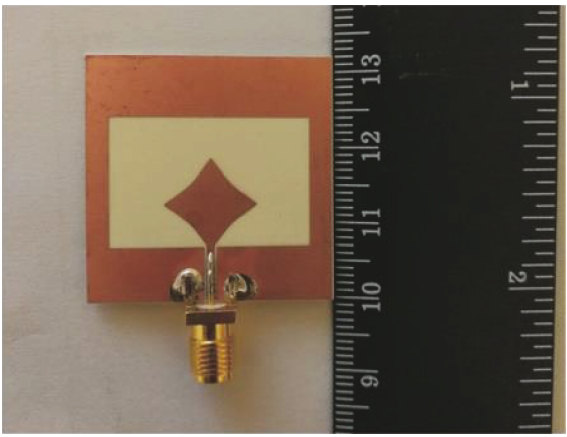

(d) Antenna 4

FIgURE 9: The fabricated antenna prototypes. 
TABLE 3: Simulated and measured bandwidth comparison.

\begin{tabular}{lccccccc}
\hline & \multirow{2}{*}{$t$} & \multicolumn{3}{c}{ Simulated } & \multicolumn{3}{c}{ Measured } \\
& & Frequency range $(\mathrm{GHz})$ & $f_{\mathrm{c}}(\mathrm{GHz})$ & Fractional bandwidth & Frequency range $(\mathrm{GHz})$ & $f_{\mathrm{c}}(\mathrm{GHz})$ & Fractional bandwidth \\
\hline Antenna 1 & 0 & $2.42-6.70$ & 4.56 & $93.9 \%$ & $2.79-6.69$ & 4.74 & $80.1 \%$ \\
Antenna 2 & 0.3 & $2.37-7.79$ & 5.08 & $106.7 \%$ & $2.80-8.46$ & 5.63 & $100.5 \%$ \\
Antenna 3 & 0.6 & $2.42-8.36$ & 5.39 & $110.2 \%$ & $2.86-9.21$ & 6.03 & $105.3 \%$ \\
Antenna 4 & 1.3 & $2.48-12.12$ & 7.3 & $132.1 \%$ & $3.05-11.70$ & 7.38 & $117.3 \%$ \\
\hline
\end{tabular}

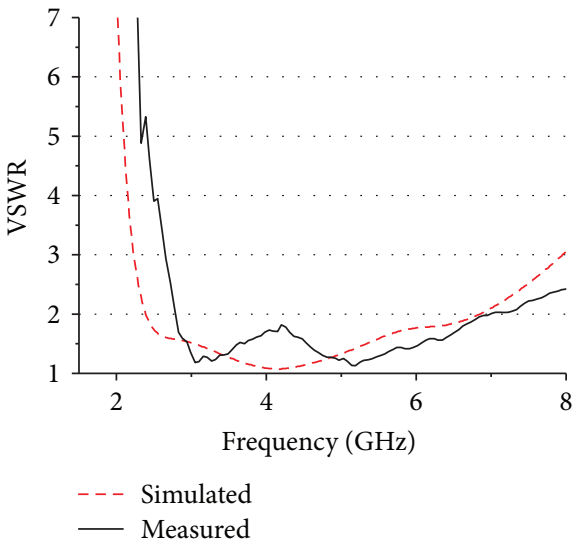

(a) Antenna 1

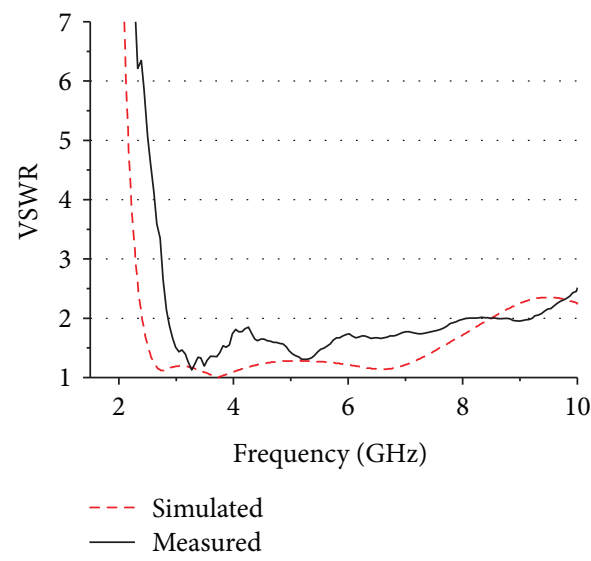

(c) Antenna 3

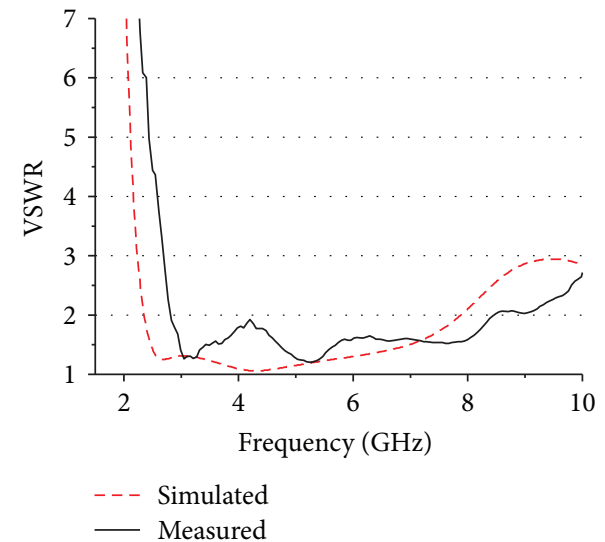

(b) Antenna 2

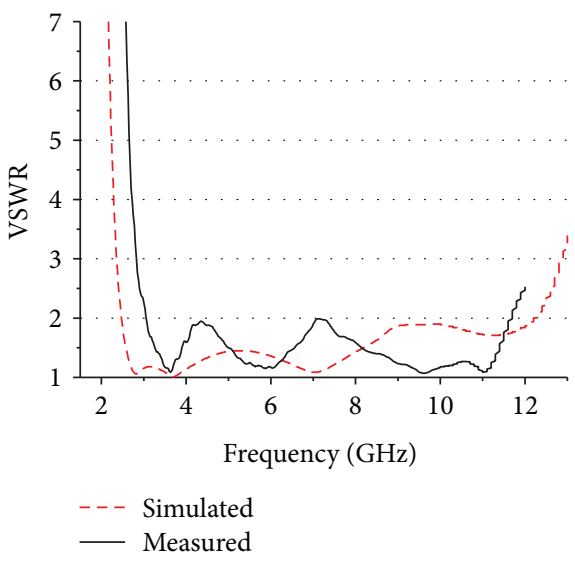

(d) Antenna 4

FIGURE 10: Simulated and measured VSWR.

bandwidth increases from $3.9 \mathrm{GHz}$ to $8.65 \mathrm{GHz}$. Meanwhile, the simulated antenna bandwidth changes from $4.28 \mathrm{GHz}$ to $9.64 \mathrm{GHz}$. The resulting measured VSWR curves are compared to the simulated ones, as illustrated in Figure 10. There are some discrepancies between the measured and the simulated VSWR curves, which is primarily due to real-world complications such as the SMA connector.

As shown in Figure 5, the antenna located in the $x-y$ plane has its normal along the $z$-axis. Figures 11 and 12 illustrate the normalized radiation patterns of both measurements and simulations at their center frequencies, (a) 4.7, (b) 5.6, (c) 6.0, and (d) $7.4 \mathrm{GHz}$, respectively. Similar bidirectional radiation properties can be observed on all the patterns in the $\mathrm{E}$ plane or $x-y$ plane. In the $\mathrm{H}$ plane or $y-z$ plane, all results show comparable omnidirectional patterns. Figure 13 shows the simulated and measured gains of the antenna prototypes. The measured results are in reasonable agreement with the simulated ones. The antennas offer stable gains $(2-6 \mathrm{dBi})$ across their operational bandwidth.

\section{Conclusion}

Various wideband antennas have been developed by using a novel shape blending method in this article. The relationship between a gradual antenna bandwidth broadening and the antenna's associated geometric dimensions, especially the blending coefficient $t$, is investigated and discussed in detail. 


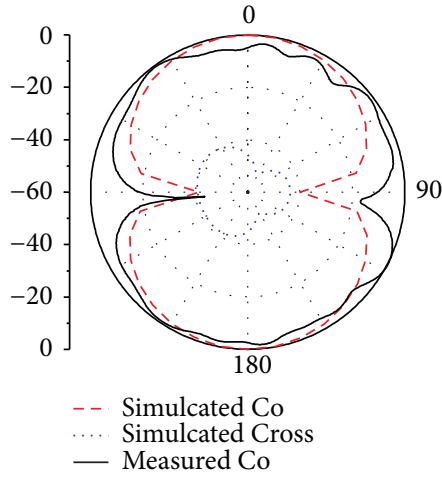

(a) Antenna $1\left(f_{c}=4.7 \mathrm{GHz}\right)$

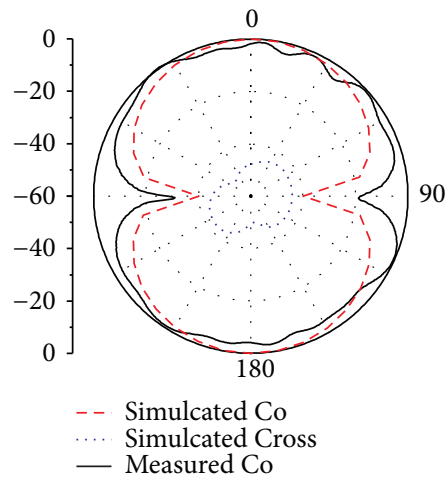

(c) Antenna $3\left(f_{\mathrm{c}}=6.0 \mathrm{GHz}\right)$

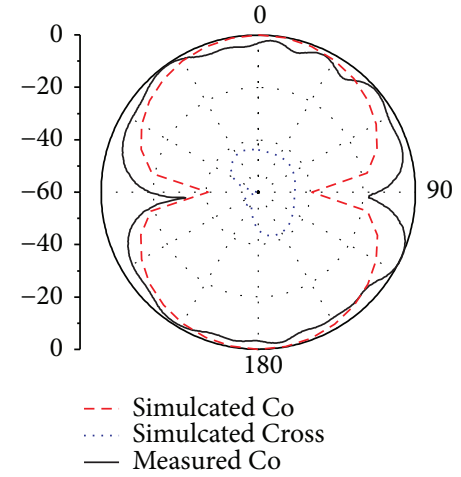

(b) Antenna $2\left(f_{\mathrm{c}}=5.6 \mathrm{GHz}\right)$

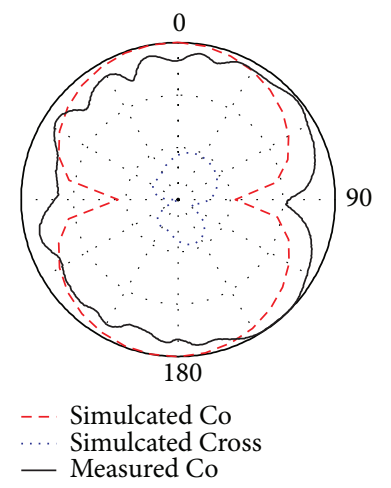

(d) Antenna $4\left(f_{\mathrm{c}}=7.4 \mathrm{GHz}\right)$

Figure 11: Simulated and measured radiation patterns in the E plane. ( $x-y$ plane).

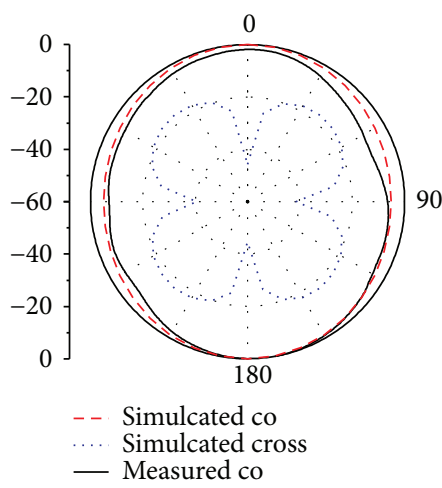

(a) Antenna $1\left(f_{\mathrm{c}}=4.7 \mathrm{GHz}\right)$
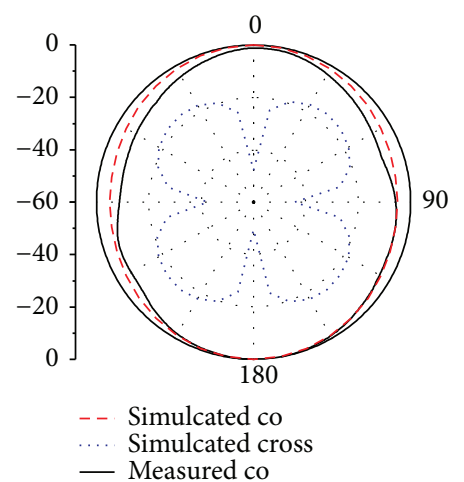

(c) Antenna $3\left(f_{\mathrm{c}}=6.0 \mathrm{GHz}\right)$

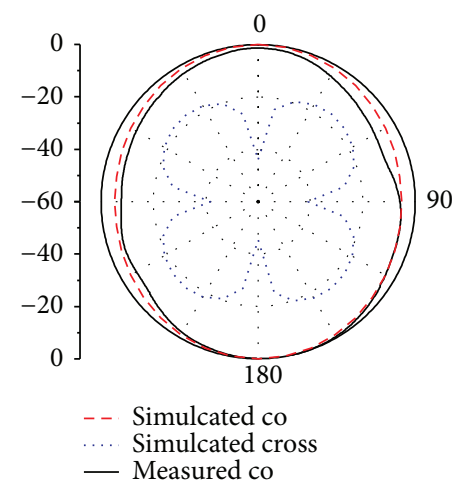

(b) Antenna $2\left(f_{\mathrm{c}}=5.6 \mathrm{GHz}\right)$

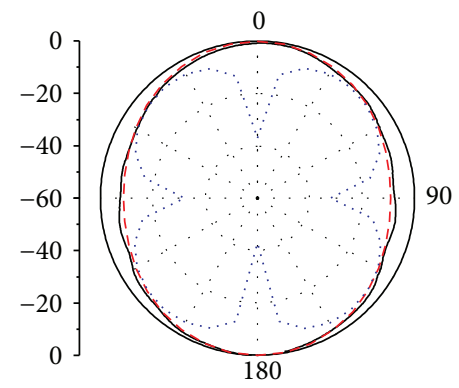

- - Simulcated co Simulcated cross Measured co

(d) Antenna $4\left(f_{\mathrm{c}}=7.4 \mathrm{GHz}\right)$

FIGURE 12: Simulated and measured radiation patterns in the H-plane ( $y$ - $z$ plane). 


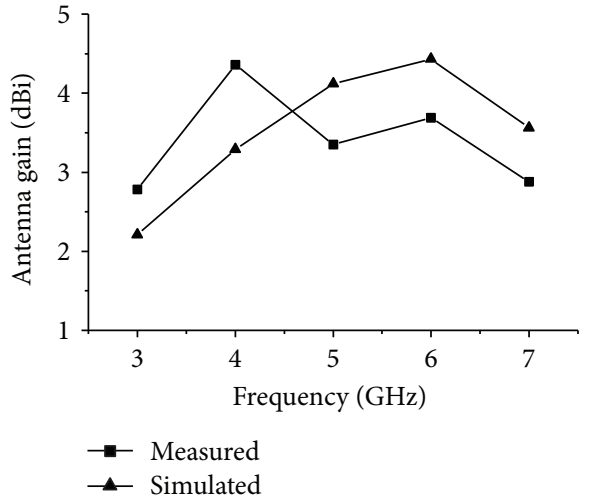

(a) Antenna 1

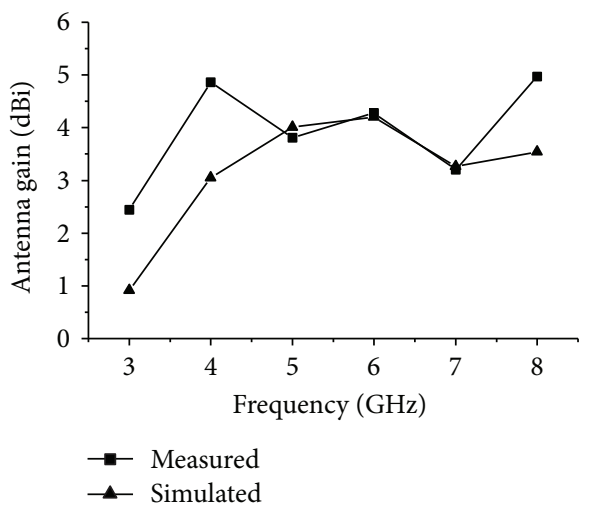

(c) Antenna 3

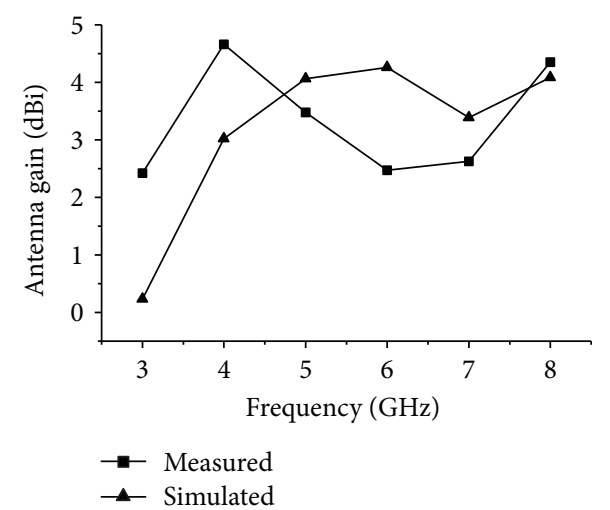

(b) Antenna 2

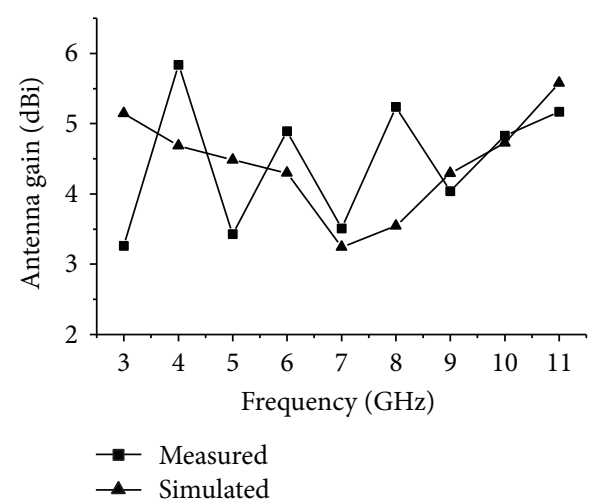

(d) Antenna 4

Figure 13: Antenna gains.

The analysis shows that by appropriately selecting the blending coefficient $t$, the proposed design can achieve the desired bandwidth. To certify the proposed antennas, four prototypes are simulated, developed, and measured. The experimental and simulated results showed good agreement with each other. We can obtain a simulated bandwidth range from $93.9 \%$ to $132.1 \%$ and a measured one from $80.1 \%$ to $117.3 \%$. The analysis and experimental results provide superb wideband antenna design processes that could be served as a wideband antenna design guide.

\section{Conflicts of Interest}

The authors declare that they have no conflicts of interest.

\section{Acknowledgments}

This work was supported by the following foundations: National Natural Science Foundation of China (Grant 61501153 and Grant 61372022) and Public Projects of Zhejiang Province (Grant 2017C31068).

\section{References}

[1] H. Nakano and J. Yamauchi, "Printed slot and wire antennas: a review," Proceedings of the IEEE, vol. 100, no. 7, pp. 21582168, 2012.
[2] T. A. Denidni and M. A. Habib, "Broadband printed CPW-fed circular slot antenna," Electronics Letters, vol. 42, no. 3, pp. 135-136, 2006.

[3] A. Chair, A. A. Kishk, and K. F. Lee, "Ultrawide-band coplanar waveguide-fed rectangular slot antenna," IEEE Antennas and Wireless Propagation Letters, vol. 3, pp. 227-229, 2004.

[4] J. William and R. Nakkeeran, "A compact CPW-fed UWB slot antenna with cross tuning stub," Progress in Electromagnetics Research C, vol. 13, pp. 159-170, 2010.

[5] J. William and R. Nakkeeran, "CPW-fed UWB slot antenna with cross like tuning stub," in Computing Communication and Networking Technologies (ICCCNT) 2010 International Conference on, pp. 1-6, Karur, India, July 2010.

[6] T. G. Ma and C. H. Tseng, "An ultrawideband coplanar waveguide-fed tapered ring slot antenna," IEEE Transactions on Antennas and Propagation, vol. 54, no. 4, pp. 1105-1110, 2006.

[7] M. Koohestani and M. Golpour, "Compact rectangular slot antenna with a novel coplanar waveguide fed diamond patch for ultra wideband applications," Microwave and Optical Technology Letters, vol. 52, no. 2, pp. 331-334, 2010.

[8] J. M. J. W. Jayasinghe, J. Anguera, D. N. Uduwawala, and A. Andújar, "Nonuniform overlapping method in designing microstrip patch antennas using genetic algorithm optimization," International Journal of Antennas and Propagation, vol. 2015, Article ID 805820, 8 pages, 2015.

[9] L. Zhang, Z. Cui, Y. C. Jiao, and F. S. Zhang, "Broadband patch antenna design using differential evolution algorithm," 
Microwave and Optical Technology Letters, vol. 51, no. 7, pp. 1692-1695, 2009.

[10] J. J. Tiang, M. T. Islam, N. Misran, and M. J. Singh, "Design of a dual-band microstrip antenna using particle swarm optimization with curve fitting," Annals of Telecommunicationsannales des télécommunications, vol. 69, no. 11-12, pp. 633-640, 2014.

[11] B. Liu, H. Aliakbarian, Z. Ma, G. A. E. Vandenbosch, G. Gielen, and P. Excell, "An efficient method for antenna design optimization based on evolutionary computation and machine learning techniques," IEEE Transactions on Antennas and Propagation, vol. 62, no. 1, pp. 7-18, 2014.

[12] S. Goudos, "Antenna design using binary differential evolution: application to discrete-valued design problems," IEEE Antennas and Propagation Magazine, vol. 59, no. 1, pp. 7493, 2017.

[13] E. D. Ülker and S. Ülker, "Antenna design using animal migration optimisation algorithm," The Journal of Engineering, vol. 2016, no. 8, pp. 298-301, 2016.

[14] X. L. Liang, T. A. Denidni, L. N. Zhang, R. H. Jin, J. P. Geng, and Q. Yu, "Printed binomial-curved slot antennas for various wideband applications," IEEE Transactions on Microwave Theory and Techniques, vol. 59, no. 4, pp. 1058-1065, 2011.

[15] S. Verma and P. Kumar, "Printed egg curved slot antennas for wideband applications," Progress in Electromagnetics Research $B$, vol. 58, pp. 111-121, 2014.

[16] S. Verma and P. Kumar, "Printed Newton's egg curved monopole antenna for ultrawideband applications," IET Microwaves, Antennas \& Propagation, vol. 8, no. 4, pp. 278-286, 2014.

[17] A. T. Wu, B. R. Guan, and Z. H. Zhang, "A wideband printed slot antenna using shape blending," in 2016 11th International Symposium on Antennas, Propagation and EM Theory (ISAPE), pp. 92-94, Guilin, China, 2016.

[18] A. T. Wu, Z. H. Zhang, and B. R. Guan, "Wideband printed antenna design using a shape blending algorithm," International Journal of Antennas and Propagation, vol. 2017, Article ID 9073765, 8 pages, 2017.

[19] T. W. Sederberg and E. Greenwood, "A physically based approach to 2-D shape blending," ACM SIGGRAPH Computer Graphics, vol. 26, no. 2, pp. 25-34, 1992.

[20] C. C. Wang, C. H. Yang, C. S. Wang, T. R. Chang, and K. J. Yang, "Feature recognition and shape design in sneakers," Computers \& Industrial Engineering, vol. 102, pp. 408-422, 2016.

[21] H. Y. Chen and H. C. Chang, "Consumers' perceptionoriented product form design using multiple regression analysis and backpropagation neural network," Artificial Intelligence for Engineering Design, Analysis and Manufacturing, vol. 30, no. 1, pp. 64-77, 2016.

[22] V. A. Shameena, S. Mridula, A. Pradeep, S. Jacob, A. O. Lindo, and P. Mohanan, "A compact CPW fed slot antenna for ultra wide band applications," AEU - International Journal of Electronics and Communications, vol. 66, no. 3, pp. 189-194, 2012.

[23] W. Wu and Y. P. Zhang, "Analysis of ultra-wideband printed planar quasi-monopole antennas using the theory of characteristic modes," IEEE Antennas and Propagation Magazine, vol. 52, no. 6, pp. 67-77, 2010.

[24] P. Li, J. Liang, and X. Chen, "Study of printed elliptical/ circular slot antennas for ultrawideband applications," IEEE Transactions on Antennas and Propagation, vol. 54, no. 6, pp. 1670-1675, 2006. 


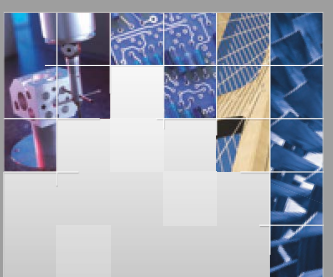

\section{Enfincering}
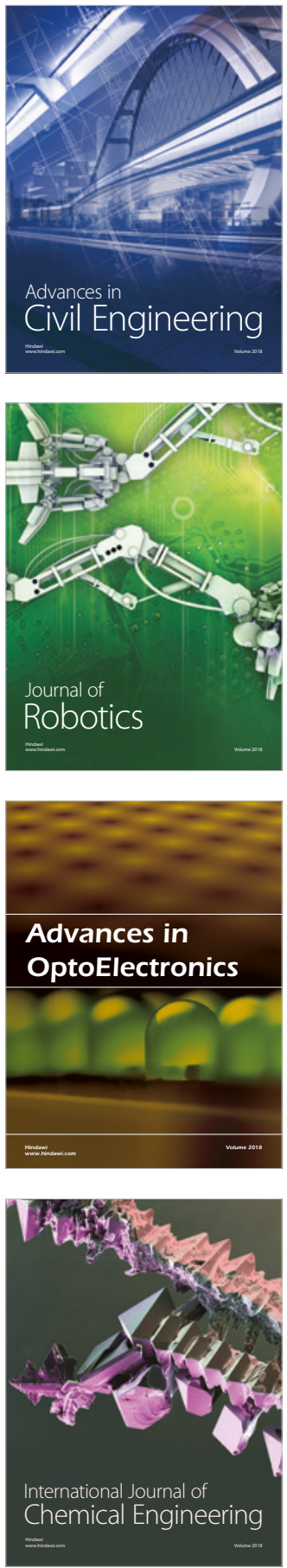

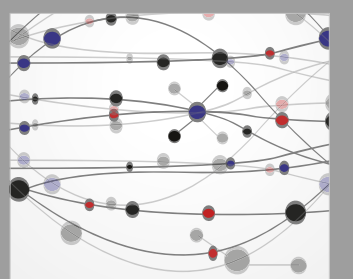

\section{Rotating \\ Machinery}

The Scientific World Journal

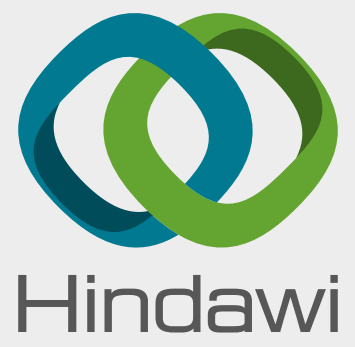

Submit your manuscripts at

www.hindawi.com
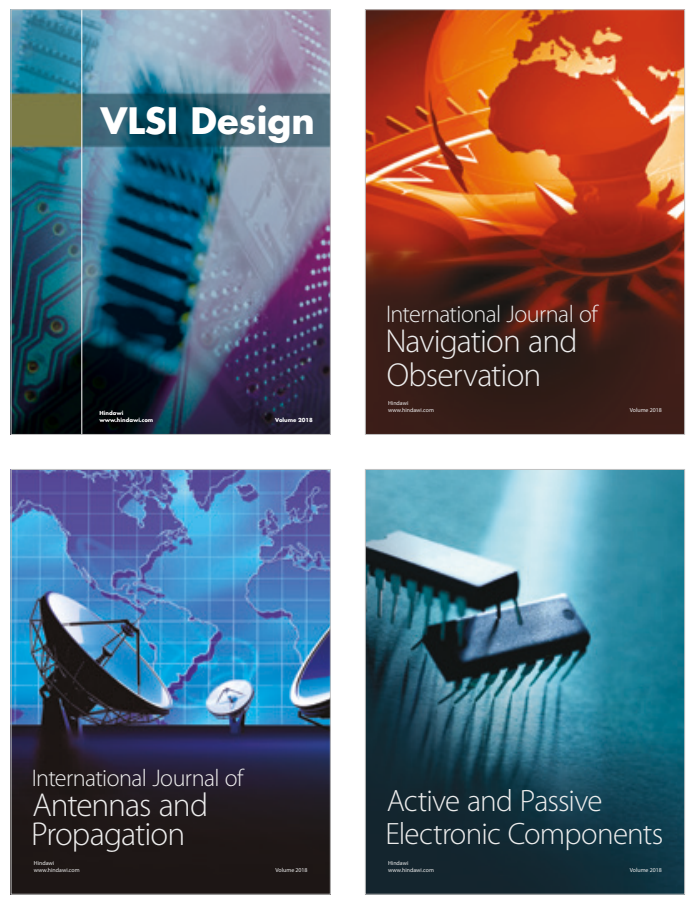
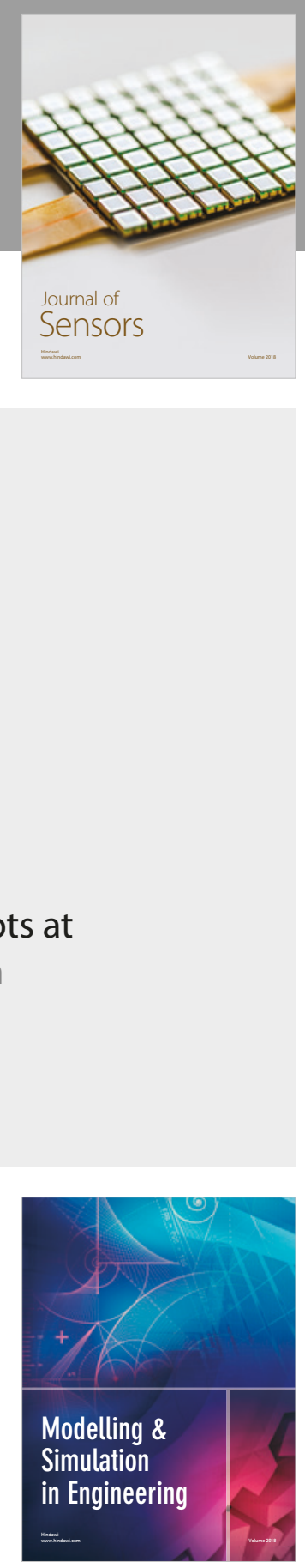

\section{Advances \\ Multimedia}
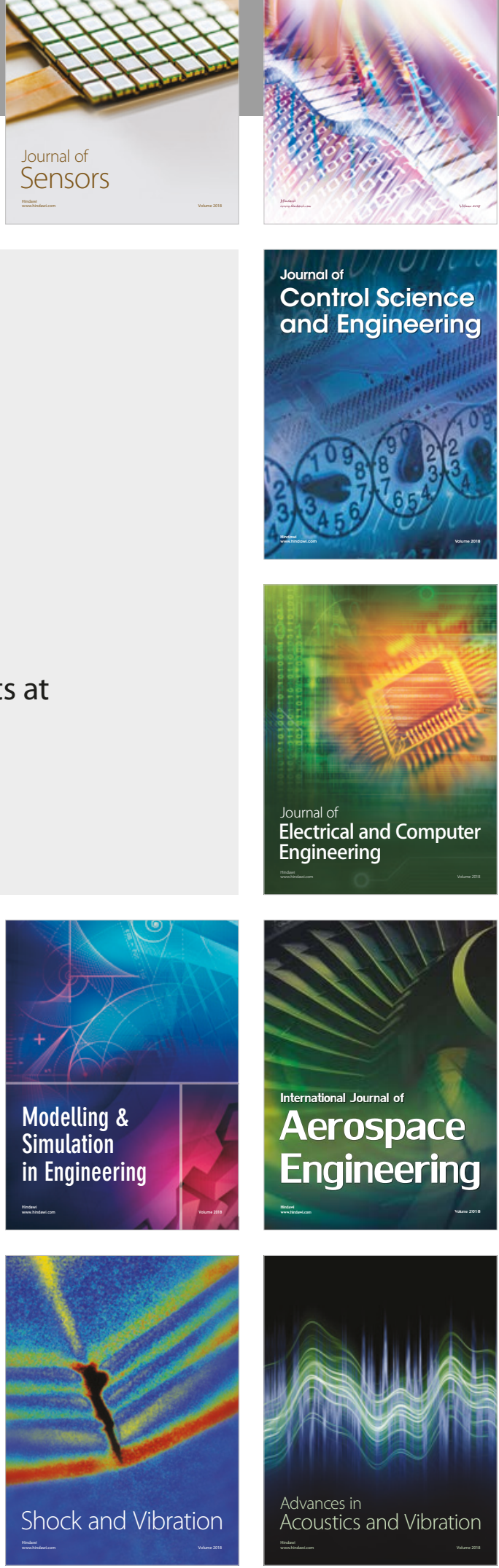